\title{
Synthesis and Crystal Structure of 1-D Coordination Polymer: $\left\{\mathrm{Na}\left[\mathrm{Eu}(2,6-\mathrm{PDA})_{2}\left(\mathrm{H}_{2} \mathrm{O}\right)_{2}\right] \cdot 3 \mathrm{H}_{2} \mathrm{O}\right\}_{\mathrm{n}}(2,6-\mathrm{PDA}=2,6$-Pyridinedicarboxylate $)$
}

\author{
Sung Kwon Kang \\ Department of Chemistry, Chungnam National University, Daejeon 305-764, Korea. E-mail: skkang@cnu.ac.kr \\ Received February 22, 2011, Accepted March 10, 2011
}

Key Words : Eu(III) complex, X-ray crystal structure, 2,6-Pyridinedicarboxylate complex, Luminescence

\begin{abstract}
Many attentions have been paid to the metal organic coordination polymers, which have been an active research area in supramolecular chemistry. The applications of such materials in the areas of gas storage, ion-exchange, catalytic, fluorescence, and magnetic properties greatly depend on the coordination nature of metals, as well as the functionality and symmetry of organic ligands. ${ }^{1}$ For the construction of coordination polymers with metals, the selection of organic ligands is very important. One of the appropriate organic ligands for the network geometries of the coordination polymers is the series of multidentate ligands containing such as oxygen and nitrogen atoms to have a great possibility for the design of multifunctional chemical architectures. ${ }^{2}$ Lanthanide complexes with organic ligands with conjugate groups have been widely studied because of the characteristic luminescent properties. Luminescent metal complexes with $\mathrm{N}$-containing ligands have been reported in the investigation of their interesting photophysical properties and various coordination modes. ${ }^{3}$ However the studies on the lanthanide complexes are more difficult than those of transition metal complexes because of high coordination number of lanthanide ions.

Pyridine carboxylates have been extensively used to prepare and design lanthanide complexes because nitrogen and oxygen atoms, which have high affinity to lanthanide ions, could be coordinated to and transfer energy to lanthanide ions. ${ }^{4}$ As an extension of our work on luminescent complexes, ${ }^{5}$ herein, we report the X-ray single crystal structure of Eu(III) complex with 2,6-pyridinedicarboxylic acid (2,6$\left.\mathrm{H}_{2} \mathrm{PDA}\right)$.
\end{abstract}

\section{Experimental Section}

Synthesis. Europium trichloride solution was prepared by dissolving $\mathrm{EuCl}_{3} \cdot 6 \mathrm{H}_{2} \mathrm{O}(0.37 \mathrm{~g}, 1.0 \mathrm{mmol}$; Aldrich $)$ in absolute ethanol $(20 \mathrm{~mL})$ at room temperature with stirring. The ligand solution was prepared by dissolving 2,6-pyridinedicarboxylic acid ( $0.33 \mathrm{~g}, 2.0 \mathrm{mmol}$; Aldrich) in absolute ethanol $(30 \mathrm{~mL})$ at room temperature. The $\mathrm{pH}$ of the ligand solution was adjusted to about 6.0 with $2 \mathrm{~N} \mathrm{NaOH}$ solution. The europium trichloride solution was added dropwise slowly to the ligand solution. The reaction mixture was stirred for 2 hours at room temperature and then the white product was filtered through a plastic membrane of $0.45 \mu \mathrm{m}$ pore size. The powder product was recrystallized from the mixture of distilled water and absolute ethanol solution to obtain colorless crystals for four weeks. Infrared spectra were recorded by the $\mathrm{KBr}$ pellet method on a Bio-Rad Lab. FTS-175C between $4,000-400 \mathrm{~cm}^{-1}$. The product was thermally decomposed at $320{ }^{\circ} \mathrm{C}$. FT-IR $\left(\mathrm{KBr}, \mathrm{cm}^{-1}\right) 3068$, $2919(\mathrm{C}-\mathrm{H}), 1633,1576(\mathrm{C}=\mathrm{O}), 1374,1285,1251(\mathrm{C}=\mathrm{C}$, $\mathrm{C}=\mathrm{N})$.

Determination and Refinement of the X-ray Structure. X-ray intensity data were collected on a Bruker SMART APEX-II CCD diffractometer using graphite monochromated Mo $K \alpha$ radiation $(\lambda=0.71073 \AA)$ at $233 \mathrm{~K}$. The data frames were integrated and scaled using Bruker package. ${ }^{6 a}$ Structure was solved by applying the direct method using a SHELXS97 and refined by a full-matrix least-squares calculation on $F^{2}$ using SHELXL-97. ${ }^{6 \mathrm{~b}}$ All non-hydrogen atoms were refined anisotropically. The $\mathrm{H}$ atoms on water molecules were located in a difference map and refined freely. The other hydrogen atoms were placed in ideal positions and were riding on their respective carbon atoms $\left(B_{\text {iso }}=1.2 B_{\text {eq }}\right)$.

Crystallographic data for the structure reported here have been deposited with the Cambridge Crystallographic Data Center (Deposition No. CCDC-813815). The data can be obtained free of charge via www.ccdc.cam.ac.uk/deposit (or from the CCDC, 12 Union Road, Cambridge CB2 1EZ, UK; Fax: +44-01223 336033; E-mail: deposit@ccdc.cam.ac.uk).

\section{Results and Discussion}

The crystallographic data and structure refinement parameters of complex 1, $\left\{\mathrm{Na}\left[\mathrm{Eu}(2,6-\mathrm{PDA})_{2}\left(\mathrm{H}_{2} \mathrm{O}\right)_{2}\right] \cdot 3 \mathrm{H}_{2} \mathrm{O}\right\}_{\mathrm{n}}$ (2,6-PDA $=2,6$-pyridinedicarboxylate) is given in Table 1 . An ORTEP diagram for complex $\mathbf{1}$ is shown in Figure 1 with the atom-numbering scheme. The structural feature of an asymmetric unit is that two 2,6-PDA and two water ligands are coordinated directly to the $\mathrm{Eu}$ atom in the inner coordination sphere forming the complex anion, while one $\mathrm{Na}$ atom as counter cation is bound to the complex anion. And there are three water molecules in the outer sphere.

In the anionic part of complex 1 , $\left[\mathrm{Eu}(2,6-\mathrm{PDA})_{2}\left(\mathrm{H}_{2} \mathrm{O}\right)_{2}\right]^{1-}$, the $\mathrm{Eu}(\mathrm{III})$ atom is nine-coordinated in a slightly distorted monocapped square antiprismatic geometry defined by four carboxylate $\mathrm{O}$ atoms, two pyridine $\mathrm{N}$ atoms, two water $\mathrm{O}$ atoms, and one more $\mathrm{O}$ atom $\left(\mathrm{O} 24^{\mathrm{i}}\right)$ from the neighboring 
Table 1. Crystal data and structure refinement for 1

\begin{tabular}{lll}
\hline Empirical formula & $\mathrm{C}_{14} \mathrm{H}_{16} \mathrm{EuN}_{2} \mathrm{NaO}_{13}$ \\
Formula weight & 595.24 \\
Temperature & $233(2) \mathrm{K}$ \\
Wavelength & $0.71073 \AA$ \\
Crystal system, space group & Monoclinic, $P 2_{1} / c$ \\
Unit cell dimensions & $a=13.978(2) \AA \quad \alpha=90^{\circ}$ \\
& $b=11.2055(19) \AA \quad \beta=102.513(3)^{\circ}$ \\
& $c=12.789(2) \AA \quad \quad \gamma=90^{\circ}$ \\
Volume & $1955.6(6) \AA^{3}$ & \\
$Z$, Calculated density & $4,2.022 \mathrm{Mg} / \mathrm{m}^{3}$ & \\
Absorption coefficient & $3.303 \mathrm{~mm}{ }^{-1}$ & \\
$F(000)$ & 1168 \\
Crystal size & $0.22 \times 0.21 \times 0.13 \mathrm{~mm}^{3}$ \\
$\theta$ range for data collection & 2.35 to $26.00^{\circ}$ \\
Reflections collected & 16707 \\
Independent reflections & $3839\left[R_{\text {int }}=0.0260\right]$ \\
Completeness to $\theta=26.00$ & $100.0 \%$ \\
Data / restraints / parameters & $3839 / 1 / 316$ \\
Goodness-of-fit on $F^{2}$ & 1.071 \\
Final $R$ indices $[I>2 \sigma(I)]$ & $R_{1}=0.0226, w R_{2}=0.0554$ \\
$R$ indices (all data) & $R_{1}=0.0281, w R_{2}=0.0588$ \\
Largest diff. peak and hole & 0.622 and $-1.076 \mathrm{e} \AA^{-3}$ \\
\hline & & \\
\hline & &
\end{tabular}
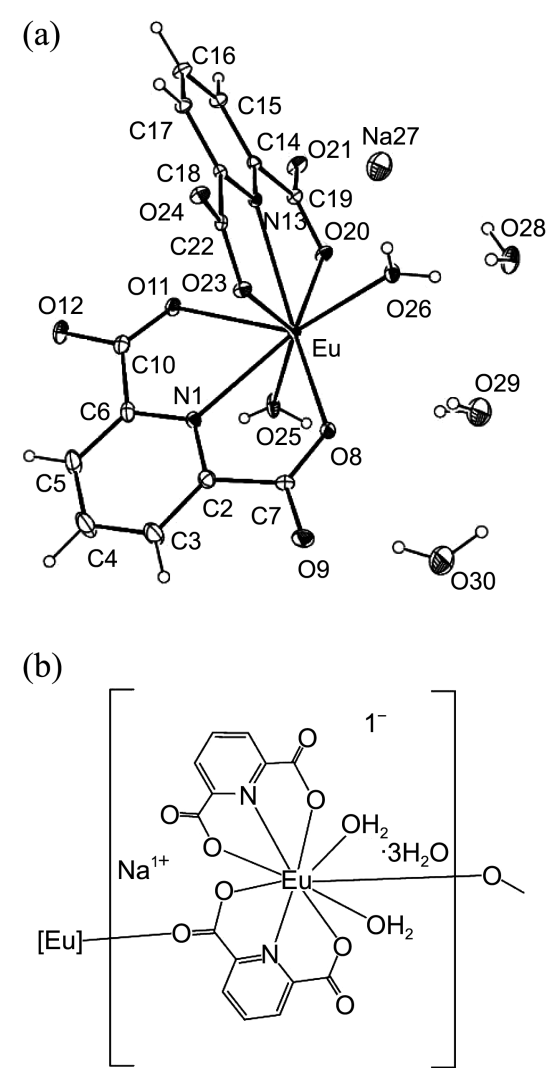

Figure 1. (a) Molecular structure of complex 1 showing the atomnumbering scheme and $30 \%$ probability ellipsoids. (b) Simple schematic drawing of asymmetric unit.

carboxylate ligand (Fig. 2). The four $\mathrm{O}$ atoms (O11, O20, $\mathrm{O} 23$, and $\mathrm{O} 26)$ and other four atoms $(\mathrm{N} 1, \mathrm{O} 8, \mathrm{O} 25$, and $\left.\mathrm{O} 24^{\mathrm{i}}\right)$ are constructed to be the distorted square antiprism

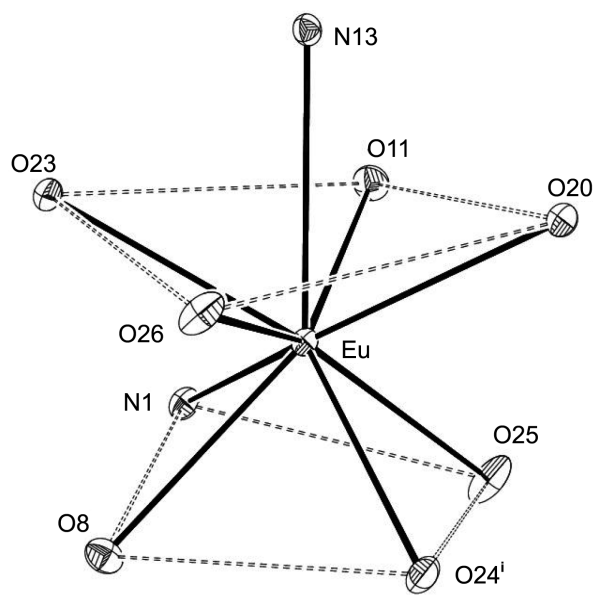

Figure 2. The coordination sphere of $\mathrm{Eu}$ atom in complex $\mathbf{1}$. Square antiprism is indicated by dashed lines. [Symmetry code: (i) $\mathrm{x},-\mathrm{y}+3 / 2, \mathrm{z}-1 / 2]$.

geometry and the other N13 atom lies on the capped position.

The bond lengths lie within the range 2.384(3)-2.507(2) $\AA$ for the Eu-O bonds and 2.558(3)-2.562(3) $\AA$ for the Eu-N bonds which are significantly shorter than the sum of the covalent radii of the Eu-O (2.660 $\AA)$ and Eu-N (2.700 $\AA)$. And these values are within the range of those observed for other nine coordinated $\mathrm{Eu}$ (III) complexes. ${ }^{4 \mathrm{a}, 5 \mathrm{~b}}$ The selected bond lengths and angles are given in Table 2. And intermolecular hydrogen-bond geometry is summarized in Table 3. The dihedral angles between pyridine rings and the carboxylate groups are in the range of $2.77(8)-14.96(17)^{\circ}$ which are

Table 2. The selected bond distances $(\AA)$ and angles $\left({ }^{\circ}\right)$ of $\mathbf{1}$

\begin{tabular}{llll}
\hline Eu-O(26) & $2.384(3)$ & Eu-O(23) & $2.501(2)$ \\
Eu-O(25) & $2.423(3)$ & Eu-O(11) & $2.507(2)$ \\
Eu-O(24) & $2.433(2)$ & Eu-N(1) & $2.558(3)$ \\
Eu-O(8) & $2.441(2)$ & Eu-N(13) & $2.562(3)$ \\
Eu-O(20) & $2.459(2)$ & & \\
& & & \\
O(11)-Eu-N(13) & $65.41(8)$ & $\mathrm{O}(20)-\mathrm{Eu}-\mathrm{O}(23)$ & $124.57(7)$ \\
$\mathrm{O}(20)-\mathrm{Eu}-\mathrm{N}(13)$ & $62.88(8)$ & $\mathrm{O}(26)-\mathrm{Eu}-\mathrm{O}(11)$ & $140.40(9)$ \\
$\mathrm{O}(23)-\mathrm{Eu}-\mathrm{N}(13)$ & $62.34(8)$ & $\mathrm{O}(25)-\mathrm{Eu}-\mathrm{O}(8)$ & $97.03(10)$ \\
$\mathrm{O}(26)-\mathrm{Eu}-\mathrm{N}(13)$ & $75.29(9)$ & $\mathrm{O}(24)^{\mathrm{i}}-\mathrm{Eu}-\mathrm{N}(1)$ & $118.96(8)$ \\
\hline
\end{tabular}

Symmetry code: (i) $x,-y+3 / 2, z-1 / 2$

Table 3. Hydrogen-bond geometry $\left(\AA,^{\circ}\right)$

\begin{tabular}{lllll}
\hline $\mathrm{D}-\mathrm{H} \cdots \mathrm{A}$ & $\mathrm{d}(\mathrm{D}-\mathrm{H})$ & $\mathrm{d}\left(\mathrm{H}^{\cdots} \mathrm{A}\right)$ & $\mathrm{d}(\mathrm{D} \cdots \mathrm{A})$ & $<(\mathrm{DHA})$ \\
$\mathrm{O}(25)-\mathrm{H}(25 \mathrm{~A}) \cdots \mathrm{O}(23)^{\mathrm{i}}$ & $0.82(2)$ & $1.94(3)$ & $2.708(4)$ & $155(5)$ \\
$\mathrm{O}(25)-\mathrm{H}(25 \mathrm{~B}) \cdots \mathrm{O}(9)^{\mathrm{ii}}$ & $0.67(5)$ & $2.07(5)$ & $2.735(4)$ & $177(6)$ \\
$\mathrm{O}(26)-\mathrm{H}(26 \mathrm{~B}) \cdots \mathrm{O}(28)^{\mathrm{iii}}$ & $0.79(5)$ & $1.99(5)$ & $2.731(4)$ & $157(4)$ \\
$\mathrm{O}(28)-\mathrm{H}(28 \mathrm{~B}) \cdots \mathrm{O}(21)^{\mathrm{iv}}$ & $0.82(6)$ & $1.86(6)$ & $2.678(4)$ & $174(6)$ \\
$\mathrm{O}(29)-\mathrm{H}(29 \mathrm{~B}) \cdots \mathrm{O}(8)$ & $0.73(7)$ & $2.22(7)$ & $2.943(4)$ & $170(8)$ \\
$\mathrm{O}(30)-\mathrm{H}(30 \mathrm{~A}) \cdots \mathrm{O}(9)$ & $0.83(6)$ & $1.81(7)$ & $2.637(5)$ & $169(6)$ \\
$\mathrm{O}(30)-\mathrm{H}(30 \mathrm{~B}) \cdots \mathrm{O}(29)$ & $0.85(7)$ & $2.23(7)$ & $2.798(6)$ & $124(6)$
\end{tabular}

Symmetry code: (i) $\mathrm{x},-\mathrm{y}+3 / 2, \mathrm{z}-1 / 2$; (ii) $-\mathrm{x}+1, \mathrm{y}+1 / 2,-\mathrm{z}+1 / 2$; (iii) $-\mathrm{x}+2,-\mathrm{y}+1,-\mathrm{z}+1$; (iv) $\mathrm{x},-\mathrm{y}+3 / 2, \mathrm{z}+1 / 2$ 


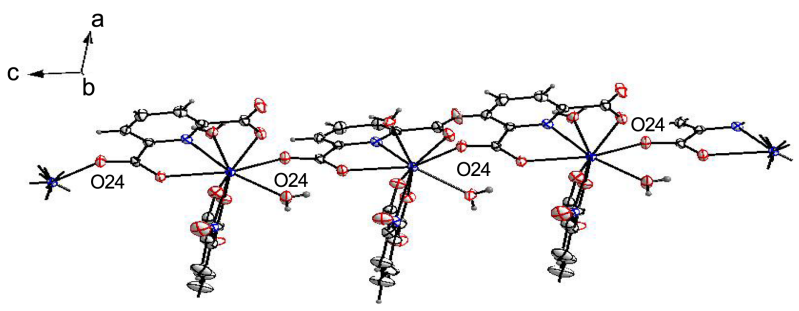

Figure 3. One-dimensional supramolecular chain along the $c$ axis.

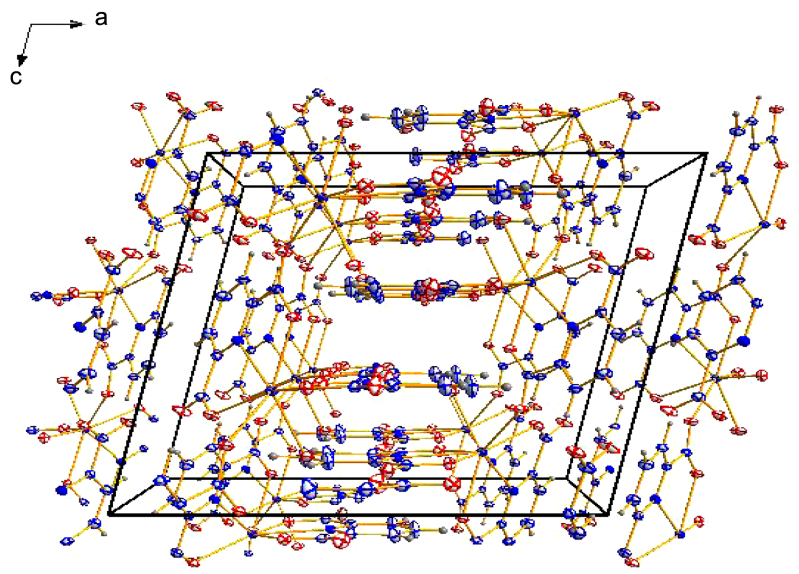

Figure 4. Three-dimensional network showing channels along the $b$ axis.

also good evidence for the interactions between the $\mathrm{O}$ atoms and $\mathrm{Eu}$ ion.

As shown the simple schematic drawing of asymmetric unit in Fig. 1(b), one of the carboxylate ligands bridges the $\mathrm{Eu}$ ions, forming a one-dimensional coordination polymer along the $c$ axis (Fig. 3). Symmetric O24 atom is directly coordinated to $\mathrm{Eu}$ (III) ions to form nine coordinated $\mathrm{Eu}$ complex with the bond distance of 2.433(2) $\AA$. Several lanthanide complexes with pyridinecarboxylate ligands have been known to form a one-dimensional (1D) chainlike structure. $^{5 b, 7}$

In the crystal structure, intermolecular $\mathrm{O}--\mathrm{H} \cdots \mathrm{O}$ hydrogen bonds (Table 3 ) link the uncoordinated water molecules to the coordinated carboxylate ligands and further link the molecules into a three dimensional network showing channels along the $b$ axis (Fig. 4).

Complex 1 emits strong red luminescence characteristic originating from the f-f transition of Eu(III) ion. Complex 1 exhibits an emission at $617 \mathrm{~nm}$ upon $396 \mathrm{~nm}$ excitation in
PL spectra with $325 \mathrm{~nm}$ of $\mathrm{He}-\mathrm{Cd}$ laser excitation wavelength. The strong emission band at $617 \mathrm{~nm}$ is corresponding to ${ }^{5} \mathrm{D}_{0} \rightarrow{ }^{7} \mathrm{~F}_{2}$ transition which is electric dipole in origin and very sensitive to crystal fields. ${ }^{8}$

In summary, the X-ray single crystal structure of complex $\left\{\mathrm{Na}\left[\mathrm{Eu}(2,6-\mathrm{PDA})_{2}\left(\mathrm{H}_{2} \mathrm{O}\right)_{2}\right] \cdot 3 \mathrm{H}_{2} \mathrm{O}\right\}_{\mathrm{n}}(\mathbf{1})$ is reported. This forms a one-dimensional (1D) coordination polymer of a chainlike structure. And in the crystal structure, weak hydrogen bonds make 3-D network frames. The coordination geometry on $\mathrm{Eu}(\mathrm{III})$ is the monocapped square antiprism with nine coordination. The luminescent studies show that the Eu complex emits strong red luminescence characteristic of the $\mathrm{Eu}^{3+}$ ion.

\section{References}

1. (a) Bai, Y. Y.; Huang, Y.; Yan, B.; Song, Y. S.; Weng, L. H. Inorg. Chem. Commun. 2008, 11, 1030. (b) Zhao, B.; Cheng, P.; Chen, X.; Cheng, C.; Shi, W.; Daizheng, L.; Yan, S.; Jiang, Z. J. Am. Chem. Soc. 2004, 126, 3012. (c) Kitaura, R.; Seki, K.; Akiyama, G.; Kitagawa, S. Angew. Chem., Int. Ed. 2003, 42, 428. (d) Hollingsworth, M. D. Science 2002, 295, 2410. (e) Leininger, S.; Olenyuk, B.; Stang, P. J. Chem. Rev. 2000, 100, 853. (f) Seo, J. S.; Whang, D.; Lee, H.; Jun, S. I.; Oh, J.; Jeon, Y. J.; Kim, K. Nature 2000, 404, 982.

2. (a) Ananias, D.; Paz, F. A. A.; Charlos, L. D.; Geraldes, C. F. G. C.; Rocha, J. Angew. Chem. Int., Ed. 2006, 45, 7938. (b) Gao, E. Q.; Yue, U. F.; Bai, S. Q.; He, Z.; Yan, C. H. J. Am. Chem. Soc. 2004, 126, 1419. (c) Hou, H. W.; Li, L, K.; Li, G. Inorg. Chem. 2003, 42, 3501 .

3. (a) Kim, Y.-I.; Seo, H.-J.; Km, J.-H.; Lee, Y.-S.; Kang, S. K. Acta Cryst. 2010, E66, m124. (b) Lis, S.; Piskula, Z.; Kubicki, M. Mater. Chem. Phys. 2009, 114, 134. (c) Godlewska, P.; Macalik, L.; Hanuza, J. J. Alloys Compd. 2008, 451, 236.

4. (a) Hong, J. H.; Oh, Y.; Kim, Y. M.; Kang, S. K.; Choi, J. W.; Kim, W. S.; Lee, J. I.; Kim, S. J.; Hur, N. H. Crystal Growth \& Design 2008, 8, 1364. (b) Yun, S. S.; Kang, S. K.; Shu, H. R.; Suh, H. S.; Lee, E. K.; Kim, J. K.; Kim, C. H. Bull. Korean Chem. Soc. 2005, 26, 1197.

5. (a) Oh, Y.; Kim, J. Y.; Kim, H. J.; Lee, T.; Kang, S. K. Bull. Korean Chem. Soc. 2010, 31, 1058. (b) Kang, S. K. Acta Cryst. 2010, E66, m1092. (c) Lee, T.; Kang, S. K. Acta Cryst. 2010, E66, m1347.

6. (a) Bruker. SADABS, SAINT, and SMART. Bruker AXS Inc., Madison, Wisconsin, USA, 2002. (b) Sheldrick, G. M. Acta Cryst. 2008, $A 64,112$.

7. (a) Abrahams, B. F.; Hudson, T. A.; Robson, R. J. Am. Chem. Soc. 2004, 126, 8624. (b) Wickleder, M. S. Chem. Rev. 2002, 102, 2011.

8. (a) Yang, T. H.; Zhou, K.; Bao, S. S.; Zhu, C. J.; Zheng, L. M. Inorg. Chem. Commun. 2008, 11, 1075. (b) Kim, Y. J.; Suh, M.; Jung, D. Y. Inorg. Chem. 2004, 43, 245. 